\title{
APPARENT SCOPE INVERSION UNDER THE RISE FALL CONTOUR*
}

\author{
KATALIN É. KISS - BEÁTA GYURIS
}

\begin{abstract}
This paper proposes an explanation of the apparent scope inversion attested in sentences pronounced with a rise fall intonation contour. It argues that a left-peripheral quantifier pronounced with a (fall-)rise is in topic position (Spec,TopP). A topic phrase must refer to an individual already present in the domain of discourse - that which will be predicated about in the sentence. Non-individual-denoting expressions, among them quantifiers, can also be made suitable for the topic role if they are assumed to denote a property which the rest of the sentence predicates some higher-order property about. A quantifier functioning as a contrastive topic denotes a property of plural individuals, and its apparent narrow scope arises from the fact that it is considered to be a predicate over a variable inherent in the lexical representation of the verb.
\end{abstract}

\section{Introduction}

The narrow scope associated with initial quantifiers in sentences pronounced with a rise fall countour has been in the focus of interest for some time (cf. Jackendoff 1972; Liberman-Sag 1974; Höhle 1991; Büring 1997; Jacobs 1997; Molnár 1998 etc.). Most recently Krifka (1998) has put forth an explanation of the phenomenon. He claims that his theory is superior to the earlier accounts because it not only derives the appropriate scope readings in the full range of cases (at least for German), but also explains the interrelation between the particular intonation contour and inverted scope. We will argue in this paper that Krifka's theory, nevertheless, cannot represent a general solution to the problem of scope inversion under the rise fall contour, because it is based on premises specific to German, which do not hold in other languages displaying the same scope inversion phenomenon, e.g., Hungarian.

* We owe thanks to Gábor Alberti, Donka Farkas, László Kálmán, Manfred Krifka, Márta Maleczki, Valéria Molnár, Chris Piñón and Anna Szabolcsi. The second author was supported by a János Bolyai Research Fellowship from the Hungarian Academy of Sciences, and by OTKA-NWO project no. N 37276. 
After summarizing the main points of Krifka's theory in section $\mathbf{1}$, the paper will point out its limitations in section $\mathbf{2}$. In sections $\mathbf{3}-\mathbf{5}$ an alternative explanation will be put forward. As section $\mathbf{3}$ will argue, the constituent associated with the rise in sentences pronounced with a rise fall contour occupies topic position (Spec,TopP). Its particular intonation expresses that it is contrasted with (a set of) alternatives. The function of the topic, namely, to denote the logical subject of predication, will be claimed to apply to this type of constituent as well; it is proposed that a quantifier in topic position denotes a property of plural individuals (in the sense of Link 1983) which the rest of the sentence predicates a higherorder property about. The contrast inherent in the interpretation of the contrastive topic requires, on the one hand, that the property it denotes and the alternative properties it is intended to be contrasted with be clearly set apart, or 'individuated', that is, their extensions be disjunct from each other, and, on the other hand, that they constitute a contextually determined set of properties. Section 4 will introduce the crucial ingredients of a compositional semantics for sentences predicating about a property. It will argue that whenever the contrastive topic expression is assumed to have a property denotation then it combines with a verb denotation which is not given in terms of an $n$-place first order predicate but in terms of a higher-order predicate which contains a property variable corresponding to the argument denoted by the contrastive topic. The idea will be supported by data analyzed by Komlósy (1992), Piñón (2001) and van Geenhoven (1996), who argue that Hungarian and other languages display in certain positions noun phrase arguments which denote properties, and which are best analyzed as combining with a verb denotation containing a property variable. Since in Hungarian any argument of a verb, regardless of its syntactic position, can be turned into the contrastive topic of the sentence, it will be claimed that every verb is associated with multiple lexical representations, which are all derivable from its basic representation as an $n$-place first-order predicate. Section $\mathbf{5}$ will show how, on the basis of the above assumptions, the interpretation of Hungarian sentences with contrastive topics can be derived compositionally, in a way which also accounts for the most puzzling feature of quantificational expressions functioning as contrastive topics: their referential variance characteristic of narrow scope quantifiers. 


\section{Krifka's theory of scope inversion}

Krifka's theory of scope inversion under the rise fall contour in German is based on two premises: on the scope assignment principle of Frey (1993), and on the assumption that a clause-initial constituent carrying the rise in a rise fall contour is a 'focus in topic', i.e., a constituent moved from a preverbal focus position into topic position. Frey's scope assignment principle states that

(1) If $\alpha, \beta$ are operators occurring in a sentence $\mathrm{S}$, then $\mathrm{S}$ has a reading in which $\alpha$ has scope over $\beta$ iff:

(a) $\alpha$ c-commands $\beta$, or

(b) $\alpha$ c-commands a trace of $\beta$.

Krifka argues that - in accordance with principle (1) - a clause-initial quantifier can have narrow scope with respect to a subsequent operator if the operator c-commands the trace of the quantifier. As for the rise fall contour of sentences displaying scope inversion, the rise realized on the initial narrow scope quantifier is not simply a rise but a rise preceded by a brief fall which can be dropped in fast speech, i.e., it is a (fall-)rise, which is represented by the iconic symbol $\sqrt{ }$ in Jacobs (1997). The (fall-)rise contour of the initial constituent opens up otherwise not existing scope interpretation possibilities because it indicates that the given constituent is a topic which has been previously focused. Focusing in German consists in the scrambling of non-focus material from between the focused constituent and the verb. The scrambled constituent will ccommand the trace of the topicalized focus; hence it can also have scope over it. This is what happens when, for example, a subject undergoes contrastive topicalization:

(2) (a) [ $\mathrm{CP}$ e [ $\mathrm{C}^{\prime}$ e [ mindestens ein Student[ jeden Roman[ gelesen]] hat]]] at least one-nom student each-acc novel read has

(b) $\left[\mathrm{CP}\right.$ e [ $\mathrm{C}^{\prime} \operatorname{hat}_{1}$ [ mindestens ein Student [ jeden Roman [ gelesen ]] $\mathrm{t}_{1}$ ]]]

(c) $\left[\mathrm{CP}\right.$ e [ $\mathrm{C}^{\prime} \operatorname{hat}_{1}\left[\right.$ jeden $\operatorname{Roman}_{2}\left[\right.$ mindestens ein Student [ $\mathrm{t}_{2}[$ gelesen $\left.\left.\left.\left.\left.]\right]\right] \mathrm{t}_{1}\right]\right]\right]$

(d) $\left[\mathrm{CP}\right.$ e $\left[\mathrm{C}^{\prime}\right.$ hat 1 [jeden Roman $_{2}\left[[\text { mindestens ein Student }]_{\mathrm{F}}\left[\mathrm{t}_{2}\right.\right.$ [gelesen]]] $\left.\left.\left.\mathrm{t}_{1}\right]\right]\right]$

(e) $\left[\mathrm{CP}[\text { mindestens ein Student }]_{\mathrm{F}, 3}\left[\mathrm{C}^{\prime}\right.\right.$ hat $\mathrm{t}_{1}$ [jeden Roman $2\left[\mathrm{t}_{3}\left[\mathrm{t}_{2}\right.\right.$ [gelesen $\left.\left.\left.\left.\left.]\right]\right] \mathrm{t}_{1}\right]\right]\right]$

(f) $\left[\mathrm{CP}[\text { mindestens ein Student }]_{\mathrm{F}, 3}\left[\mathrm{C}^{\prime}\right.\right.$ hat $1[\text { [jeden Roman }]_{\mathrm{F}, 2}\left[\mathrm{t}_{3}\left[\mathrm{t}_{2}\right.\right.$ [gelesen $\left.\left.\left.\left.\left.]\right]\right] \mathrm{t}_{1}\right]\right]\right]$ 'At least one student has read every novel.' 
After verb second in $(2 \mathrm{~b})$, jeden Roman is scrambled out of the preverbal focus position so as to give way to subject focus (2c). After its removal, the focus feature is assigned to the subject (2d), which is topicalized afterwards (2e), and becomes a 'focus in topic'. (Molnár 1998 arrives at a similar conclusion.) The (fall-)rise intonation is a combination of the intonation patterns associated with the topic and the focus functions. Since the trace of mindestens ein Student is c-commanded by jeden Roman, the narrow scope reading of mindestens ein Student is correctly predicted. Jeden Roman ends up preverbally, where it assumes a focus feature $(2 \mathrm{f})$.

\section{Limitations of Krifka's theory}

A problem raised by Krifka's theory is that we attest similar scope inversion facts also in other languages, for instance in Hungarian, where the premises from which scope inversion follows in Krifka's framework are not satisfied. Consider the Hungarian equivalent of Krifka's (2f).

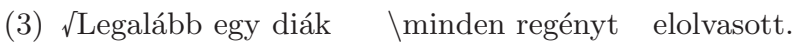

at least one student every novel-acc read

'At least one student read \every novel.'

For Krifka's explanation to go through in Hungarian, it ought to be shown that (i) Frey's scope principle is operative in Hungarian, and (ii) a contrastive topic is focused prior to topicalization.

As for scope interpretation, in Hungarian all operators are preposed into A-bar positions on the left periphery of the proposition-hence all operators c-command the proposition, including the traces of their clausemates. For example, distributive quantifiers, among them universals, are preposed to the specifiers of Distributive Phrases - see É. Kiss (1991; 1994); Beghelli-Stowell (1997); and Szabolcsi (1997b). Consequently, Frey's scope interpretation principle would predict scope relations to be free. In fact, just the opposite is true: scope relations are disambiguated in Hungarian. Preverbal operators have scope precisely over the domain they c-command and precede; i.e., their scope order corresponds to their surface order. Thus the readings that are provided under (4a) and (4b) do not represent merely the most likely readings of these sentences; they represent their only readings: 
(4) (a) [DistP Csaknem mindegyik könyvet [DistP több diák is [vP elolvasta]]] nearly every book-acc several student even read 'It holds of nearly every book that it was read by several students.'

(b) [DistP Több diák is [DistP csaknem mindegyik könyvet [VP elolvasta]]] 'It holds of several students that they read nearly every book.' 1

(Is translated as 'even' is a functional element which turns the element associated with it into a distributive quantifier. A constituent supplied with is must land in distributive quantifier position (Spec,DistP), and can only have a distributive reading. On $i s$ phrases as distributive universal quantifiers, see Hunyadi 1984.)

As for focus assignment in Hungarian, it involves the A-bar movement of the focus constituent into a preverbal operator position (Spec, $\mathrm{F}$ (ocus)P according to Brody 1990). Movement of a contrastive topic through Spec,FP, and then the filling of Spec,FP by another constituent would violate the Strict Cycle Condition, a version of which also figures in the Minimalist Program (cf. Chomsky 1995, 190). Furthermore, there are various types of constituents which can easily function as contrastive topics, but cannot be focussed. Such are universal quantifiers, which have a designated landing site in Spec,DistP. Since the universal quantifier is ungrammatical as a focus - see (5a), a universal quantifier associated with the (fall-)rise contour - e.g., that in (5b) — cannot be a topicalized focus.

(5) (a) *[TopP János [FP MINDEN REGÉNYT olvasott el]]

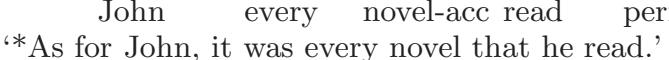

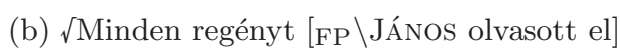
'All novels were read BY \JoHN.'

It is possible, however, that the preverbal focus figuring in Krifka's theory is actually not the identificational focus occupying a VP-external operator position in Hungarian but is an information focus, a stressed constituent, which can occur in the Hungarian VP, as well (cf. É. Kiss 1998). So it is conceivable that the structural moves that Krifka pos-

\footnotetext{
${ }^{1}$ This is exactly the reason why the explanation for the narrow scope of contrastive topics proposed by Büring (1997) would not go through in Hungarian, either. Büring (1997) assumes that all types of contrastive topics are ambiguous with respect to scope assignment, while in Hungarian only the denotation of contrastive topics which are referential expressions can be determined independently of the denotation of the quantificational expression following them in the sentence; nonreferential contrastive topics obligatorily take narrow scope.
} 
tulates may take place in the VP in Hungarian, after all. However, the claim that a contrastive topic is a topicalized focus could not be maintained in Hungarian under this assumption, either. Notice, for example, that existential quantifiers of the vala- 'some-' type cannot be focussed in any sense; they not only cannot be moved to Spec,FP - see (6a), but cannot bear focus stress in the VP, either - see (6b). ((6b), with valaki 'somebody' stressed, can only be interpreted as a metalinguistic correction, or a twisted, emotionally loaded statement.) Nevertheless, valatype quantifiers can function as contrastive topics - see (7).

(6) (a) *[DistP Mindenki [FP VALAKIT hívott meg]]

$$
\text { everybody somebody-acc invited perf }
$$

'*It was somebody that everybody invited.'

(b) ?[DistP Mindenki [meg hívott VALAKIT]]

'?Everybody invited sOMEBODY.'

(7) $\sqrt{ }$ Valakit \mindenki meghívott.

'Somebody was invited by \everybody.'

Krifka (1998) does not actually claim that his theory is of cross-linguistic validity; he calls his theory an explanation of scope inversion under the (fall-)rise intonation in German. Since, however, the (fall-)rise contour of a clause-initial quantifier licenses scope inversion across languages, a generalization appears to be lost if the parallel facts are explained in different ways in every language.

Below we propose an explanation of scope inversion under the (fall-) rise fall contour which, though demonstrated on Hungarian facts, is of cross-linguistic validity. Like Krifka's theory, our explanation will also correlate the narrow scope and the (fall-)rise contour of an initial quantifier - although it will derive the correlation from different premises. The explanation to be proposed hinges on the claim that quantifiers pronounced with a (fall-)rise are contrastive topics, whose scope interpretation is a consequence of semantic properties derivable from their contrastive topic function. ${ }^{2}$ So the first step in our analysis is the discussion of the syntactic and semantic properties of the contrastive topic.

\footnotetext{
${ }^{2}$ Our proposal is related to the analyses of Jackendoff (1972) and Jacobs (1997) in this respect. Jackendoff claims that a sentence like All men |didn't go expresses a statement about its contrastive topic; it states that the topic does not have the property denoted by the comment. In the assertion the negation has scope over the element all, which is expressed by stress. Jacobs (1997) calls the apparent narrow scope of initial quantifiers under the (fall-)rise contour an epiphenomenon.
} 


\section{The contrastive topic in Hungarian}

\subsection{Structural position}

In Hungarian linguistics it has been a matter of discussion for decades what position constituents pronounced with the contrastive (fall-)rise contour, among them quantifiers undergoing scope inversion, occupy in the richly structured left periphery of the Hungarian sentence. They are clearly neither in the pre-VP focus position (Spec,FP), the canonical position of negative existential quantifiers, nor in a pre-FP quantifier position (Spec,Dist(ributive)P), the canonical position of universal quantifiers. Consider first a negative existential quantifier pronounced with the (fall-)rise contour. Whereas a regular negative existential quantifier, occupying Spec,FP, cannot be followed by (another) focus - see (8a,b), a negative existential quantifier pronounced with a (fall-)rise can-see (9).

(8) (a) [FP \KEVÉS DIÁK bukott meg kémiából]

few student failed perf chemistry-in

'It was few students who failed in chemistry.'

(b) *[FP \KEVÉS DIÁK [FP \KÉMIÁBÓL bukott meg]]

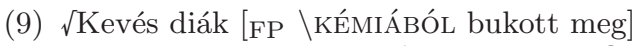

'Few students failed in \CHEMIstry. [It was chemistry that few students failed in.]'

Neither negative existential quantifiers in Spec,FP, nor universal quantifiers in Spec,DistP can precede sentence adverbials - see (10a,b). Quantifiers pronounced with a (fall-)rise, on the other hand, sound natural also before a sentence adverbial - see (11).

He claims that such sentences consist of a topic and a predicate in the scope of an assertion operator:

(i) $\llbracket$ ASSERT $^{\mathrm{IT}}$ (TOP)(PRED)』

In the propositional content of the sentence the denotatum of PRED is applied to TOP as an argument, which yields (ii):

\section{(ii) $\llbracket \mathrm{PRED} \rrbracket(\llbracket \mathrm{TOP} \rrbracket)$}

It is structure (ii), with the topic functioning as an argument of the predicate, that creates the effect of scope inversion. Scope inversion is a consequence of a syntactic configuration in which the trace of the topic is in the c-command domain of a predicateinternal operator. 
(10) (a) Tudomásom szerint [DistP \minden diák $\quad$ [FP CSAK \KÉMIÁBÓL bukottmeg]] to.my.knowledge every student only chemistry-infailed perf 'To the best of my knowledge every student failed only in chemistry.'

(b) ??[DistP \Minden diák tudomásom szerint [FP CSAK \KÉMIÁBÓL bukott meg]] 'Every student to the best of my knowledge failed only in chemistry.'

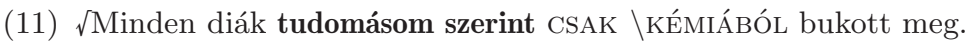
'All students to the best of my knowledge failed ONLY IN \CHEMISTRY. [To the best of my knowledge it was only chemistry that all students failed in.]'

Functionally, the Hungarian sentence falls into two main units: the predicate part, represented by a verb phrase optionally extended by negation into a NegP, by a focus into an FP, and/or by distributive quantifiers into a DistP, and the topic part, represented by one or more noun phrases, whose referent(s) the predicate part is predicated about. Sentence adverbials must be external to the predicate part; they can appear before, after, or between the topic noun phrases, as (12) displays.

(12)

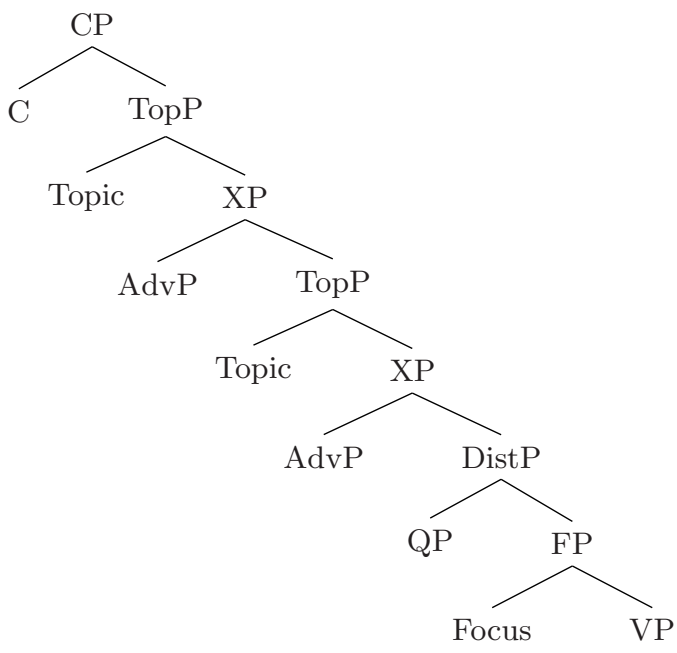

Given that a constituent pronounced with the (fall-)rise contour can precede sentence adverbials, the question is whether it is a topic sitting in Spec,TopP, or a further structural position should be established for it on the left periphery of the sentence. As Alberti and Medve (2000) showed, the plausibility of the latter view is diminished by the fact that a constituent with the (fall-)rise contour can either precede or follow a noncontrastive topic, or can also intervene between topicalized constituents. 
Observe in (13a-c) the possible orders of the quantifier minden kollégáját, pronounced with the (fall-)rise contour, and the two non-contrastive topics: János and a születésnapjára.

(13) (a) $\sqrt{\text { Minden kollégáját } \quad J a ́ n o s ~ a ~ s z u ̈ l e t e ́ s n a p j a ́ r a ~ \ n e m ~ s z o k t a ~ m e g h i ́ v n i . ~}$ every colleague.of.his-acc John his birthday.on not used to.invite 'Every colleague of his, John would \not invite for his birthday.'

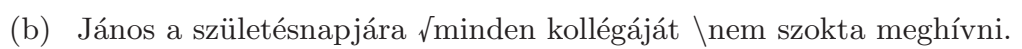

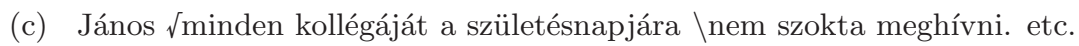

Since in the Hungarian sentence functional projections have a fixed order, the internal order of topicalized constituents, on the other hand, is free, the logical conclusion to be drawn on the basis of $(14 \mathrm{a}-\mathrm{c})$ is that constituents pronounced with a (fall-)rise contour, among them narrow scope quantifiers, are in topic position; they are contrasted/contrastive topics.

\subsection{Function and properties}

In the language type represented by Hungarian, a topicalized constituent pronounced with regular topic prosody must refer to an individual that is already present in some sense (i.e., at least indirectly) in the universe of discourse. This follows from the nature of topic function: a topic foregrounds an individual from the universe of discourse in order to be predicated about (on the topic function, see Kuroda 1972; Sasse 1987; and É. Kiss 1994; 1995).

Non-individual-denoting elements, among them quantifiers, cannot be external to the predicate part of the sentence - unless they are pronounced with a (fall-)rise contour. Therefore, if a quantifier pronounced with a (fall-)rise indeed occupies topic position and functions as a topic (i.e., as the logical subject of predication), it must be the contrastive (fall-)rise contour that exempts it from the individuality requirement. This conclusion is also confirmed by facts of Japanese, a language representing the same topic-prominent type as Hungarian. According to the Japanese grammar of Kuno (1973), a constituent marked by the topic morpheme $w a$ is either referential/generic or contrastive. ${ }^{3}$ In other words, a non-R expression, when supplied with the wa morpheme, must

${ }^{3}$ If generic NPs are names of kinds, as claimed by Carlson (1977), then they are also referential, denoting specific individuals. 
be interpreted contrasted, and must receive contrastive intonation (Kuno 1973, 47). Consider Kuno's examples (21a-d) on pp. 46-47:

(14) (a) *Ame wa hutte imasu. rain topic falling is 'Speaking of rain, it is falling.'

But:

(b) Ame wa hutte imasu ga, taisita koto wa arimasen. rain topic falling is but serious matter topic not.exists 'It is raining, but it is not much.'

(15) (a) *Oozei no hito wa party ni kimasita. many people topic party to came 'Speaking of many people, they came to the party.'

But:

(b) Oozei no hito wa party ni kimasita ga, many people topic party to came but omosiroi hito wa hitori mo imasen desita. interesting people topic one person even was.not

'Many people came to the party indeed, but there was none who was interesting.'

The Japanese analogy suggests that a constituent in topic position denoting something other than a specific individual may, indeed, function as a topic, and, furthermore, the licensing of non-individual-denoting expressions as topics must be related to the contrast expressed by their (fall-)rise contour.

Sentences containing a contrastive topic introduce the implicature that there is at least one alternative statement to the one expressed by the sentence which is neither entailed nor contradicted by the latter (for a more detailed discussion on the advantages of the above way of formulating the implicature, as opposed to that proposed in Büring 1997, see Gyuris 2002). The relevant alternative statements are generated by exchanging the denotation of the contrastive topic and that of the predicate for alternatives in the sense of Rooth (1985). Let us illustrate the workings of the above procedure by means of the following examples:

(16) (a) JJánosra \számítok.

John-on count-I

'On John, I \do count.'

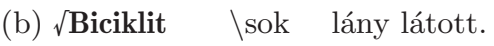

bicycle-acc many girl saw

'Bicycles, \many girls saw.' 


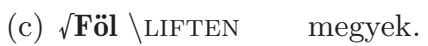
up elevator-on go-I 'Up, I go by \elevator.'

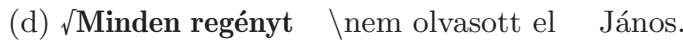
every novel-acc not read perf John 'Every novel, John has \not read.' First-order representation: $\neg \forall \boldsymbol{x}(\operatorname{novel}(x) \rightarrow \operatorname{read}(\mathbf{j}, x))$

The contrasted topic of (16a) is a name. The sentence is a statement about its referent, János; it states about János that I count on him. The contrastive (fall-)rise associated with Jánosra implicates that there is at least one alternative statement having the structure 'I count on $x$ ' or 'do not count on $x$ ', where $x$ is a member of the same set as John, whose truth is neither entailed nor contradicted by the truth of (16a). In the present situation, this amounts to saying that the sentence implicates that there is a person on whom I do not count. In the case of the above example, the alternative to the predicate was generated by negating the predicate. In the case of a negated predicate, as in (16d), the alternative is its non-negated counterpart. If the VP is preceded by a focus, as in (16c), the alternative predicate is generated by replacing the value of the focus operator expressing exhaustive identification with a different value (i.e., a different member of the set on which the focus operator operates). If the predicate contains a quantifier, the alternative predicate is generatedroughly - by replacing the quantifier with a different one - see (16b).

(16b) is a statement about the property 'bicycle'; it states that many girls saw a representative of it. The common noun bicikli, expressing a property, inherently does not denote a distinct individual, hence it does not satisfy the condition of movement into topic position, and association with the falling intonation typical of regular topics. In (16b), however, it is used as the name of a property, functioning as the subject of predication. (So that it can be contrasted with alternative properties, it has to be properly individuated, i.e., its extension has to be separated from the extensions of the intended alternative properties, naturally.) (16b) can thus be paraphrased as follows:

(17) 'Of the set of currently relevant properties, the one named in Spec,TopP is under consideration. It is stated about it that many girls saw a representative of it. It is implicated that there is at least one alternative statement about a different member of the same set which is neither entailed nor implicated by the latter (e.g., one stating that the property of being seen by few girls applies to at least one representative of it).' 
(17) expresses the intuition that (16b) is a statement about the property 'bicycle', i.e., biciklit functions as a topic.

(16c), too, contains an inherently non-individual-denoting topic, the verbal particle föl 'up'. Föl can also be topicalized only if it is individuated through contrasting. The fact that it is set into a tacit contrast with its counterpart denoting the opposite direction, le 'down', makes it clear that we use it as the name of a direction. The sentence means the following:

(18) 'Of the set of currently relevant directions, the one named in Spec,TopP is under consideration. It is stated about it that I will go there by elevator. It is implicated that the truth of the sentence is compatible with the truth of at least one proposition predicating an alternative property about the downward direction (the only alternative of the contrastive topic denotation), i.e., that I go there by some other means.'

Whereas a universal quantifier cannot be topicalized under the normal topic intonation, it can be used as a contrastive topic. We will claim that the clause-initial quantifier pronounced with a (fall-)rise contour in (16d), just like those in (3) and (5b), is a contrastive topic, which does not denote the maximal set of individuals, or a generalized quantifier (i.e., a set of sets of individuals), but either the maximal individual in the extension of the noun (in the relevant situation) or a property of plural individuals, the property of being the sum of all entities with the property of being a book in the relevant situation. We will argue that the apparent narrow scope of the topicalized expression minden könyvet 'every book-acc' is a consequence of the fact that it denotes a specific individual or a property. ${ }^{4}$

${ }^{4}$ Note that the lack of interpretations (perceived as ill-formedness) for the variant of the above sentence with an affirmative predicate, shown in (i) below, can be explained by saying that there is no alternative statement introduced by this sentence which is not entailed by it. In other words, if all novels were read by John, then all alternative propositions of the form $N$ novels were read by John would be true and all of the form It is not true that $N$ novels were read by John would be false for $\mathrm{N} \leq$ all, thus the contrastive topic would not give rise to the required implicature.

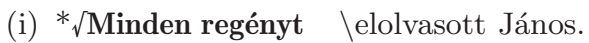

every novel-acc perf-read John

\#'Every novel, John \has read.'

Note, however, that if in (i) the contrastive intonation falls on the noun, then the alternatives introduced by the contrastive topic would be maximal individuals of 


\section{Property-denoting contrastive topics and sentence interpretation}

\subsection{Properties as noun phrase denotations}

In the previous sections we claimed that contrastive topic constituents which do not refer to individuals denote properties. Naturally, certain types of quantified expressions, like the contrastive topic of (19) below, may have both a referential reading and a property-denoting reading when used as contrastive topics:

(19) $[$ Spec,TopP $\sqrt{\text { Két diákot] }} \quad \backslash$ nem láttam.
two student-acc not saw-I

(a) 'Two students, I \didn't see.' (It is not true that I saw two students.)

(b) 'Two particular students, I \didn't see.' (It is not true that I saw two particular students.)

In the rest of the paper we will focus on the property-denoting interpretation of contrastive topic noun phrases, illustrated in the (19a) reading, and ignore the referential reading, shown in (19b). ${ }^{5}$

The assumption that contrastive topics denote properties, however, turns out to be incompatible with the traditional assumption that verbs correspond to $n$-place first-order predicates, since the property-denotation of the contrastive topic argument cannot be combined with the traditional verbal denotation into a sentence-denotation, i.e., a proposition, by means of functional application. (20) illustrates the extensional representation of the property which corresponds to the (a) reading of the contrastive topic of (19), and (21) shows the representation of the meaning of the verb in (19) as an extensional first-order predicate.

\footnotetext{
a type which could be considered an alternative of novel, i.e., poem, newspaper, etc., and with this intonation sentence (i) does introduce the required implicature.

${ }^{5}$ If we make quantification over events explicit, reading (19a) in fact corresponds to two readings which are paraphrasable as 'It is not the case that there was an event involving me seeing two students' and as 'It is not the case that there were two students such that there were events involving me seeing them', respectively. In view of the fact that here we are not following the (neo-)Davidsonian tradition of making events part of the ontology of our semantic representation language, the above two types of readings become indistinguishable. We believe, however, that this fact does not influence the validity of the claims presented here.
} 
(20) $\llbracket$ két diák $\rrbracket=\lambda \boldsymbol{x}$ TWO-STUDENT $(\boldsymbol{x})$

(21) \lát $=\lambda \boldsymbol{y} \lambda \boldsymbol{x} \operatorname{saw}(\boldsymbol{x}, \boldsymbol{y})$

The property shown in (20) above is the property of being a sum of at least two students. The issue of how the appropriate properties are generated for particular contrastive topic noun phrases will be discussed in section $\mathbf{4 . 3}$.

One possible way to ensure that the denotations of the contrastive topic and the VP, shown in (20) and (21), can be combined by means of function-argument application is to lift the type of the VP in (21) to a type which contains a property-variable, and thus can be applied to the contrastive topic denotation in (20).

The traditional assumption that the verbs of the language correspond to $n$-place first-order predicates has been challenged in several proposals before, some of which, particularly those pertaining to Hungarian, will be considered in the rest of this section.

Komlósy (1992) discusses the interpretation of sentences where the internal arguments of verbs are represented by bare nominals, which are not assumed to name or identify a particular object, but to name a particular property of the internal argument of the verb. (22) shows an example:

(22) Péter újságot olvas.

Peter newspaper-acc reads

'Peter is reading a newspaper.'

According to Komlósy (1992), the meaning of the bare nominal object in (22) is to be represented as in (23a), and the meaning of the verb would be as in (23b). These denotations, composed together by functional application, result in the formula in (24), corresponding to the meaning of the sentence:

(23) (a) újságot 'newspaper-acc': $\lambda \boldsymbol{y}$ newspaper $\left(\boldsymbol{y}_{\boldsymbol{o b j}}\right)$

(b) olvas 'reads': $\lambda \boldsymbol{F} \lambda \boldsymbol{x} \exists \boldsymbol{y}\left[\operatorname{read}\left(\boldsymbol{x}, \boldsymbol{y}_{\boldsymbol{o b j}}\right) \wedge \boldsymbol{F}(\boldsymbol{y})\right]$

(24) $\exists \boldsymbol{x}[\operatorname{read}(\mathbf{p}, \boldsymbol{x}) \wedge \operatorname{newspaper}(\mathrm{x})]$

Komlósy claims that verb denotations of type (23b) are always available whenever the verb can have a bare nominal argument, and are derivable 
from the two-place first-order predicate denotations, e.g., $\lambda \boldsymbol{y} \lambda \boldsymbol{x} \operatorname{read}(\boldsymbol{x}, \boldsymbol{y})$, by means of a lexical process.

According to Piñón (2001), a set of Hungarian verbs, the so-called definiteness effect verbs, lack the 'regular' $n$-place first order predicate denotation altogether, and can only denote predicates over properties. The verb evett 'ate' in (25) counts as a definiteness effect verb:

(25) Anna evett egy almát.

Anna ate an apple-acc

'Anna ate an apple.'

Piñón (2001) proposes that definiteness effect verbs should be considered as functions applying to a predicate (or property) argument. In his framework, the meaning of the verb of (25) would be represented (ignoring the dynamicity of the existential quantifier) in the following way:

(26) evett $_{\text {def-eff }}$ 'eat' $\Rightarrow \lambda \boldsymbol{P} \lambda \boldsymbol{x} \lambda \boldsymbol{e}\left[\exists \boldsymbol{y}\left[\boldsymbol{e} \boldsymbol{a t} \boldsymbol{t}^{\prime}(\boldsymbol{e}, \boldsymbol{x}, \boldsymbol{y}) \wedge \boldsymbol{P}(\boldsymbol{y})\right]\right]$

Van Geenhoven (1996) investigates noun incorporation in West Greenlandic. She claims that from a semantic point of view, West Greenlandic incorporated nouns are indefinite descriptions, which only denote a property. (27) below is the general formula she uses to represent the meaning of a verb which forms a complex together with an incorporated noun:

(27) $\lambda \boldsymbol{P}_{\langle\mathrm{s},\langle\mathrm{e}, \mathrm{t}\rangle\rangle} \lambda \boldsymbol{w}_{\boldsymbol{s}} \lambda \boldsymbol{x}_{\boldsymbol{e}} \exists \boldsymbol{y}\left[\operatorname{Verb}_{\boldsymbol{w}}(\boldsymbol{x}, \boldsymbol{y}) \wedge \boldsymbol{P}_{\boldsymbol{w}}(\boldsymbol{y})\right]$

According to van Geenhoven, the meaning of an incorporated noun is absorbed into the meaning of an incorporating verb due to the fact that the former is assumed to denote a property, represented by the variable $\boldsymbol{P}$ in (27), of the verb's internal argument.

Van Geenhoven links the behaviour of West Greenlandic incorporated nouns to other indefinite constructions in other languages as well, namely, to bare plurals in West Germanic languages, and German split topics. She claims that the narrow scope effects characteristic of these three constructions can be given a uniform explanation, namely: they are instances of semantically incorporated, predicative indefinite descriptions, the existential interpretation of which is due to the verb itself. They cannot be interpreted as definite or partitive, since the variable representing the indefinite is always novel, so it cannot pick up a salient referent. 
In his review of a version of van Geenhoven's theory (1996), Cohen (1999) argues that the verbs of a language should be regarded as ambiguous between an incorporating reading and an ordinary $n$-place predicate interpretation, which is supported by the fact that in the Germanic languages verbs can combine with both bare plurals and with other noun phrases.

In this section we have reviewed three theories which claim-either about a particular class of verbs (those displaying the definiteness effect), or about verbs taking arguments of a particular syntactic category (bare nominal) and semantic type (property) - that their lexical representation is not given in terms of an $n$-place predicate but contains a property variable. That is why such verbs can take an argument denoting a property in the first place. In view of the fact that there are many verbs in the language which can take bare nominal arguments as well as full noun phrase arguments, it seems to be a reasonable assumption to postulate a lexical rule which maps for each verb its ordinary $n$-place predicate denotation into a denotation with property variables.

Having examined some constructions in which noun phrase arguments have been assumed to denote properties, in the next section we consider what characteristic features contrastive topic noun phrases share with argument types which have previously been assumed to denote properties.

\subsection{The property-reading of contrastive topics}

The argument types which have been argued in the literature to denote properties cannot be regarded as definite or partitive, that is, they cannot be taken to be anaphoric expressions linked to some salient object. This property is shared by non-referential topics as well. In the following sentence, for example, the object noun phrase does not necessarily identify a particular referent, as reading (a) shows:

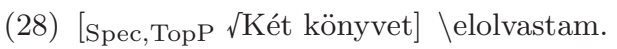

two book-acc read-1sg

(a) 'Two books, I \did read.'

(b) 'Two particular books, I \did read.'

(29) illustrates a similar case: 


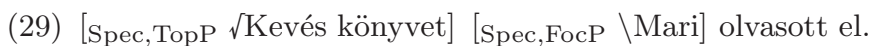

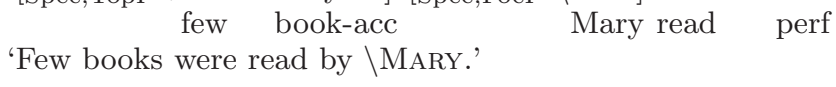

The above sentence does not mean that Mary is the person who read particular books which are few in number, but that if there is an individual who has read few books, then it is identical to Mary. (Due to the fact that the noun phrase Mari is in focus position, the sentence presupposes that there is indeed an individual who read few books.) The fact that (29) cannot be continued the way shown in (30) proves that the above claim is correct:

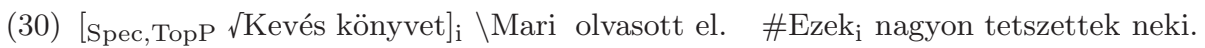
few book-acc Mary read perf these very pleased her 'Few booksi were read by $\backslash$ MARY. She liked them*i a lot.'

The following example illustrates that in certain cases there is no individual which the contrastive topic expression could identify at all, but the sentence is still well-formed:

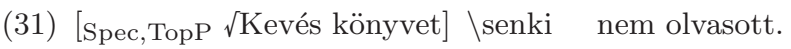

few book-acc nobody not read

'Few books were read by \nobody.'

(31) would be uttered as an answer to a question like the following one, for example:

(32) Ki olvasott \kevés könyvet?

who read few book-acc

'Who read few books?'

(31) expresses that the property of being few books cannot be predicated of any individual read by anyone. This interpretation markedly differs from the one the same DP receives in sentences like (33) below, where, as Szabolcsi (1997b, 122) claims, it "performs a counting operation on the property denoted by the rest of the sentence:"

(33) Mari [Spec,? \kevés könyvet] olvasott.

Mary few book-acc read

'Mary read few books.'

Having argued that postulating a property-reading for contrastive topic DPs does not contradict the assumptions which property-denoting expressions have traditionally been associated with in the literature, in the 
next section we will show how the property-denotations are derived for particular contrastive topic DPs.

\subsection{Defining the properties denoted by contrastive topic DPs}

The property denoted by the contrastive topic of (28) above, két könyvet 'two books-acc', is the property of being a sum of at least two atomic individuals which fall into the denotation of book. Thus, it corresponds to the property of being the sum of elements in the intersection of a set in the generalized quantifier denotation of the DP and the set corresponding to the nominal denotation. (For an arbitrary DP, such a set is normally referred to as a witness of the generalized quantifier corresponding to the DP. ${ }^{6}$ The property-denotation of két könyvet 'two books' is represented formally as follows:

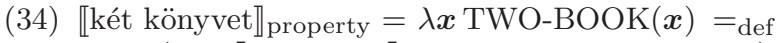
$\lambda \boldsymbol{x} \exists \boldsymbol{S}\left(\boldsymbol{S} \in \llbracket\right.$ two books $\rrbracket_{\mathrm{GQ}} \wedge \boldsymbol{S} \subseteq$ book $\left.\wedge \boldsymbol{x}=\sqcup \boldsymbol{S}\right)(\boldsymbol{x})$

(34) means that the property denotation of két könyvet 'two books-acc' is a property of sums of individuals, abbreviated as TWO-BOOK, which is defined as the property of being the sum of individuals in a set which is an element of the generalized quantifier denotation of two books, i.e., the set of sets of atomic individuals which have at least two books as elements, and which is a subset of the denotation of book, i.e., the set of (atomic) books. The formula in (35) shows a possible way how (34) could be generalized to the case of an arbitrary DP:

(35) the property-denotation of arbitrary DPs - first version

$\llbracket$ Det NP $\rrbracket_{\text {property }}=\lambda \boldsymbol{x} \mathrm{DET}-\mathrm{NP}(\boldsymbol{x})=_{\mathrm{def}}$

$\lambda \boldsymbol{x} \exists \boldsymbol{S}\left(\boldsymbol{S} \in \llbracket\right.$ Det NP $\left.\rrbracket_{\mathrm{GQ}} \wedge \boldsymbol{S} \subseteq \llbracket \mathrm{NP}_{\text {sing }} \rrbracket \wedge \boldsymbol{x}=\sqcup \boldsymbol{S}\right)(\boldsymbol{x})$

(35) means that the property-denotation of a DP would be a property of plural individuals which constitute the sum of a set of atomic individuals which falls into the generalized quantifier denotation of the DP and is a subset of the denotation of the constituent noun phrase. This generalization will have to be modified in the light of data illustrating the

${ }^{6}$ Witness sets of generalized quantifiers correspond to those elements of the set of sets in the generalized quantifier denotation which are subsets of the smallest set the generalized quantifier lives on, cf. Szabolcsi (1997a). 
interpretation of DPs with non-monotonic or monotone decreasing determiners (cf. Barwise-Cooper 1981) in contrastive topic position. Before turning to these data, however, let us consider the issue of how the assignment of property-denotations to arguments influences the interpretation of the verbs they appear together with in the sentence.

\subsection{The lexical representation of verbs with contrastive topic arguments}

It has been claimed that the contrastive topic arguments of verbs can denote properties of plural individuals. It has also been demonstrated that there is no restriction on the syntactic category (bare nominal versus full DP) or thematic role of the argument of the verb which plays the contrastive topic role. In view of these considerations, we suggest that all verbs in the language can be analyzed as predicates over property denotations, which can correspond to any of the arguments of a verb. From the fact that a verb can have several arguments, it follows that each verb in the language must be associated with several denotations, which should all be derivable from its basic $n$-place predicate denotation-although the nature of the type-raising mechanisms which can generate the former denotations from the latter will not be discussed. Thus, the meaning of transitive verbs in Hungarian will be analyzed in terms of the following formulae:

(36) (a) $\lambda y_{\mathrm{e}} \lambda \boldsymbol{x}_{\mathrm{e}} \operatorname{verb}(\boldsymbol{x}, \boldsymbol{y})$

(b) $\lambda \boldsymbol{P}_{\langle\mathrm{e}, \mathrm{t}\rangle} \lambda \boldsymbol{x}_{\mathrm{e}} \exists \boldsymbol{y}[\operatorname{verb}(\boldsymbol{y})(\boldsymbol{x}) \wedge \boldsymbol{P}(\boldsymbol{y})]$

(c) $\lambda \boldsymbol{y}_{\mathrm{e}} \lambda \boldsymbol{P}_{\langle\mathrm{e}, \mathrm{t}\rangle} \exists \boldsymbol{x}[\operatorname{verb}(\boldsymbol{y})(\boldsymbol{x}) \wedge \boldsymbol{P}(\boldsymbol{x})]$

The first two denotations are more or less similar to those proposed for West Greenlandic by van Geenhoven (1996). Contrary to van Geenhoven, however, we will assume that the individual variables can stand for both atomic and plural individuals in the join semilattice corresponding to the denotation of the common noun. 


\section{Deriving the apparent narrow scope of contrastive topics}

\subsection{Contrastive topic DPs with monotone increasing determiners}

In this section we analyze examples which show how the apparent narrow scope reading of contrastive topic noun phrases falls out from the premises discussed above. Consider first example (37), and a standard first-order representation of its denotation on the non-specific reading of the contrastive topic (which assumes that individual variables stand for atomic individuals only) in (38):

(37) [Spec,TopP $\sqrt{K e ́ t ~ k u t y a ́ t] ~ \ n e m ~ l a ́ t o t t ~ M a r i . ~}$ two dog-acc not saw Mary

'Two dogs, Mary \did not see.'

(38) $\neg \exists \boldsymbol{x} \exists y(\operatorname{dog}(\boldsymbol{x}) \wedge \operatorname{dog}(\boldsymbol{y}) \wedge \boldsymbol{x} \neq \boldsymbol{y} \wedge \operatorname{saw}(\mathbf{m}, \boldsymbol{x}) \wedge \operatorname{saw}(\mathbf{m}, \boldsymbol{y}))$

The syntactic structure of (37) is shown in (40) below. The representation employs a convention used in Reinhart (1983), Rooth (1985), Cresti (1993) and Heim-Kratzer (1998), according to which the actual binder of the trace of a moved phrase is the index of the moved phrase, and which is defined in Cresti $(1993,92)$ as follows:

(39) MOVEMENT INDICES

Structures of the form XP $\mathrm{XP}_{\mathrm{i}} \mathrm{YP}$ are rebracketed as XP i $\mathrm{YP}_{\mathrm{YP}}$, and i YP translates as $\lambda \mathrm{v}_{\mathrm{i}} \beta$, where $\beta$ is the translation of $\mathrm{YP}$, and $\mathrm{v}_{\mathrm{i}}$ is the same variable that was chosen for the translation of $t_{i}$ inside YP.

(40)

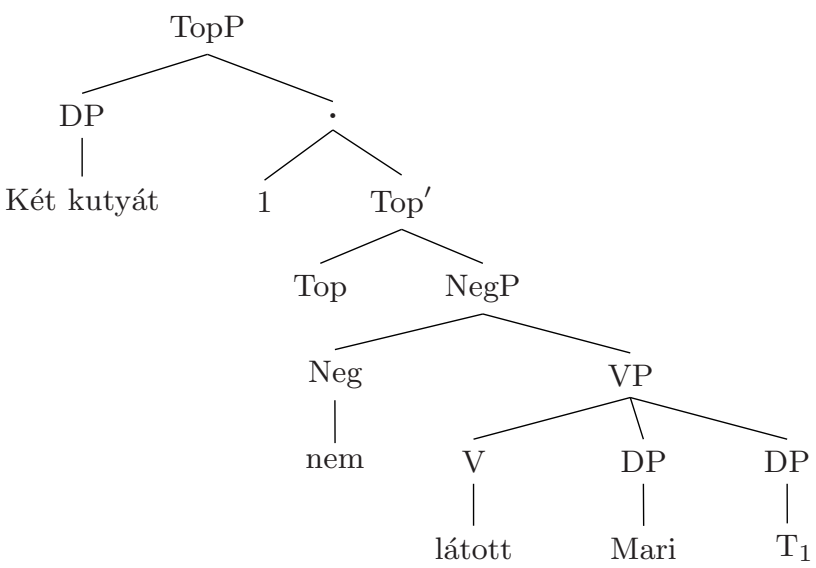


In (40) above, $\mathrm{T}_{1}$ signals the trace of the moved constituent with a higherorder (property) denotation. (41) shows the proposed denotations for some of the nodes of the syntactic tree:

(41) (a) $\llbracket \mathrm{V} \rrbracket=\lambda \boldsymbol{P}_{\langle\mathrm{e}, \mathrm{t}\rangle} \lambda \boldsymbol{x}_{\mathrm{e}} \exists \boldsymbol{y}_{\mathrm{e}}[\operatorname{saw}(\boldsymbol{x}, \boldsymbol{y}) \wedge \boldsymbol{P}(\boldsymbol{y})]$

(b) $\llbracket \mathrm{VP} \rrbracket=\exists y\left[\operatorname{saw}(\mathbf{m}, \boldsymbol{y}) \wedge \boldsymbol{Q}_{\boldsymbol{i}}(\boldsymbol{y})\right]$

(c) $\llbracket \mathrm{NegP} \rrbracket=\neg \exists \boldsymbol{y}\left[\operatorname{saw}(\mathbf{m}, \boldsymbol{y}) \wedge \boldsymbol{Q}_{\boldsymbol{i}}(\boldsymbol{y})\right]$

(41a) shows the denotation of the verb (with its object argument denoting a property), and (41b) that of the VP resulting from the combination of the verb with its subject and object arguments. (41c) shows the denotation of the negated VP, which, due to the fact that the Top head is not associated with any specific meaning component, corresponds to the denotation of the Top' projection as well. The denotation of the node dominating Top', generated on the basis of convention (39), labelled by ' $\quad$ in the tree, is the following:

(42) $\lambda \boldsymbol{Q}_{i} \neg \exists y\left[\operatorname{saw}(\mathbf{m}, \boldsymbol{y}) \wedge \boldsymbol{Q}_{\boldsymbol{i}}(\boldsymbol{y})\right]$

Combining (42) with the property-denotation of the contrastive topic, abbreviated as $\lambda \boldsymbol{z}_{\mathrm{e}}$ TWO-DOG( $\left.\boldsymbol{z}\right)$, and defined according to the pattern in (39) via function-argument application, gives us (43) as the denotation of the whole sentence:

(43) $\lambda \boldsymbol{Q}_{i} \neg \exists \boldsymbol{y}\left[\operatorname{saw}(\mathbf{m}, \boldsymbol{y}) \wedge \boldsymbol{Q}_{\boldsymbol{i}}(\boldsymbol{y})\right]\left(\lambda \boldsymbol{z}_{\mathrm{e}} \mathrm{TWO}-\mathrm{DOG}(\boldsymbol{z})\right)=$ $\neg \exists \boldsymbol{y}[\operatorname{saw}(\mathbf{m}, \boldsymbol{y}) \wedge \mathrm{TWO}-\mathrm{DOG}(\boldsymbol{y})]$

The truth-conditional equivalence between (38) and (43) can easily be shown if the saw relation is assumed to satisfy the properties in (44), where ${ }_{i} \sqsubseteq$ denotes the individual-part relation:

(44) (a) $\forall \boldsymbol{x} \forall \boldsymbol{y} \forall \boldsymbol{y}^{\prime}\left(\left(\operatorname{saw}(\boldsymbol{x}, \boldsymbol{y}) \wedge \operatorname{saw}\left(\boldsymbol{x}, \boldsymbol{y}^{\prime}\right)\right) \rightarrow \operatorname{saw}\left(\boldsymbol{x}, \boldsymbol{y} \sqcup \boldsymbol{y}^{\prime}\right)\right)$

(b) $\forall \boldsymbol{x} \forall \boldsymbol{y} \forall \boldsymbol{y}^{\prime}\left(\left(\operatorname{saw}(\boldsymbol{x}, \boldsymbol{y}) \wedge \boldsymbol{y}^{\prime}{ }_{\mathrm{i}} \sqsubseteq \boldsymbol{y}\right) \rightarrow \operatorname{saw}\left(\boldsymbol{x}, \boldsymbol{y}^{\prime}\right)\right)$

(44a) means that whenever there is an individual which stands in the saw relation with two individuals, then it stands in the same relation with the sum of these individuals, whereas (44b) means that whenever there is an individual which stands in the saw relation with another individual, then it stands in the same relation with all the individual parts of the latter. 
By the same procedure, and on the basis of the same assumptions, the narrow scope reading of the contrastive topic noun phrase in the following sentence, which is paraphrased in (45a), can also be explained:

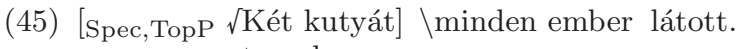

two dog-acc every person saw

(a) 'Two dogs were seen by \everybody.' (i.e., 'Everybody saw two dogs.')

(b) 'There are two particular dogs which were seen by everybody.'

(46) shows the traditional first-order representation of reading (45a), with variables standing for atomic individuals, and (47) represents the syntactic structure of the sentence:

(46) $\forall x(\operatorname{person}(x) \rightarrow \exists y \exists z(\operatorname{dog}(y) \wedge \operatorname{dog}(z) \wedge y \neq z \wedge \operatorname{saw}(x, y) \wedge \operatorname{saw}(x, z)))$

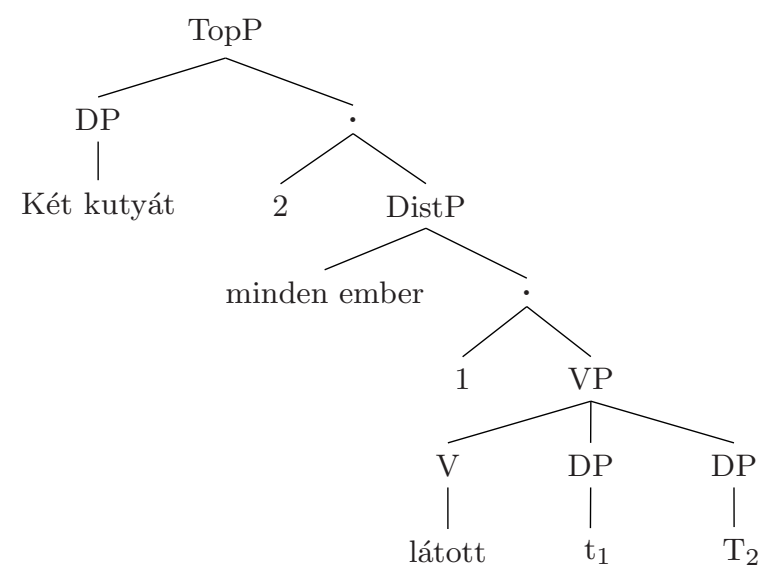

The denotation of the VP node can now be given in terms of the formula in (48).

(48) $\llbracket \mathrm{VP} \rrbracket=\exists y\left[\operatorname{saw}(\boldsymbol{z}, \boldsymbol{y}) \wedge \boldsymbol{Q}_{\boldsymbol{i}}(\boldsymbol{y})\right]$

(49a) shows the denotation of the node dominating the VP (generated according to convention (39)) which, combined by means of functionargument application with the denotation of the universal noun phrase in (49b) (in which the predicate AT only applies to atomic individuals), results in the formula corresponding to the denotation of the DistP node, shown in (49c). 
(49) (a) $\lambda \boldsymbol{z} \exists y\left[\operatorname{saw}(z, y) \wedge Q_{\boldsymbol{i}}(\boldsymbol{y})\right]$

(b) $\lambda \boldsymbol{P}_{\langle\mathrm{e}, \mathrm{t}\rangle} \forall \boldsymbol{x}[[\operatorname{person}(\boldsymbol{x}) \wedge \mathrm{AT}(\boldsymbol{x})] \rightarrow \boldsymbol{P}(\boldsymbol{x})]$

(c) $\lambda \boldsymbol{P}\left\langle\right.$ e, t $\forall x[[\operatorname{person}(x) \wedge \operatorname{AT}(x)] \rightarrow P(x)]\left(\lambda z \exists y\left[\operatorname{saw}(z, y) \wedge Q_{i}(y)\right]\right)=$ $=\forall \boldsymbol{x}\left[[\operatorname{person}(\boldsymbol{x}) \wedge \mathrm{AT}(\boldsymbol{x})] \rightarrow \exists \boldsymbol{y}\left[\operatorname{saw}(\boldsymbol{x}, \boldsymbol{y}) \wedge \boldsymbol{Q}_{\boldsymbol{i}}(\boldsymbol{y})\right]\right]$

Note that since the individual-level variables are assumed to stand for both atomic and plural individuals here, in (49b) above it is indicated explicitly that the domain of the universal quantifier includes atomic individuals only. (50a) shows the denotation of the node dominating DistP, whereas (50b) indicates how it is combined by means of functional application with the property-denotation of the contrastive topic:

(50) (a) $\lambda \boldsymbol{Q}_{\boldsymbol{i}} \forall \boldsymbol{x}\left[\left[\operatorname{person}^{\prime}(\boldsymbol{x}) \wedge \mathrm{AT}(\boldsymbol{x})\right] \rightarrow \exists \boldsymbol{y}\left[\operatorname{saw}^{\prime}(\boldsymbol{x}, \boldsymbol{y}) \wedge \boldsymbol{Q}_{\boldsymbol{i}}(\boldsymbol{y})\right]\right]$

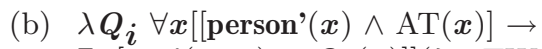

$\left.\exists \boldsymbol{y}\left[\operatorname{saw}^{\prime}(\boldsymbol{x}, \boldsymbol{y}) \wedge \boldsymbol{Q}_{\boldsymbol{i}}(\boldsymbol{y})\right]\right](\lambda \boldsymbol{x}$ TWO-DOG $(\boldsymbol{x}))=$

$=\forall \boldsymbol{x}\left[\left[\right.\right.$ person' $\left.\left.\left.^{\prime} \boldsymbol{x}\right) \wedge \mathrm{AT}(\boldsymbol{x})\right] \rightarrow \exists \boldsymbol{y}\left[\operatorname{saw}^{\prime}(\boldsymbol{x}, \boldsymbol{y}) \wedge \mathrm{TWO}-\mathrm{DOG}(\boldsymbol{y})\right]\right]$

Assuming that the relation denoted by saw has the properties defined in (44) above, the truth-conditional equivalence between (50b) and (46) follows: if for any atomic individual with the person property there are at least two atomic individuals in the denotation of $d o g$ which the former stands in the saw relation with, then any atomic individual with the person property will be such that it stands in the saw relation with an individual in the semilattice of dogs with at least two atomic parts, and vice versa.

In the following example, the role of contrastive topic is played by a noun phrase which is normally taken to express universal quantification. (52) shows the syntactic structure associated with (51):

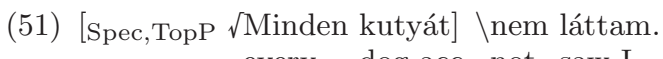
every dog-acc not saw-I

'Every dog, I \didn't see.'

We propose that when such a universal DP appears as a contrastive topic, it either denotes an individual or a property, as other contrastive topics do. The denotation of the sentence, however, would be the same proposition on both interpretations. If the DP denotes an individual, it is the maximal individual in the semilattice corresponding to the denotation of the noun, as proposed by Maleczki (1995). This individual can directly combine with the property-denotation of the predicate, and thus the proposition corresponding to the meaning of the sentence is the 
$(52)$

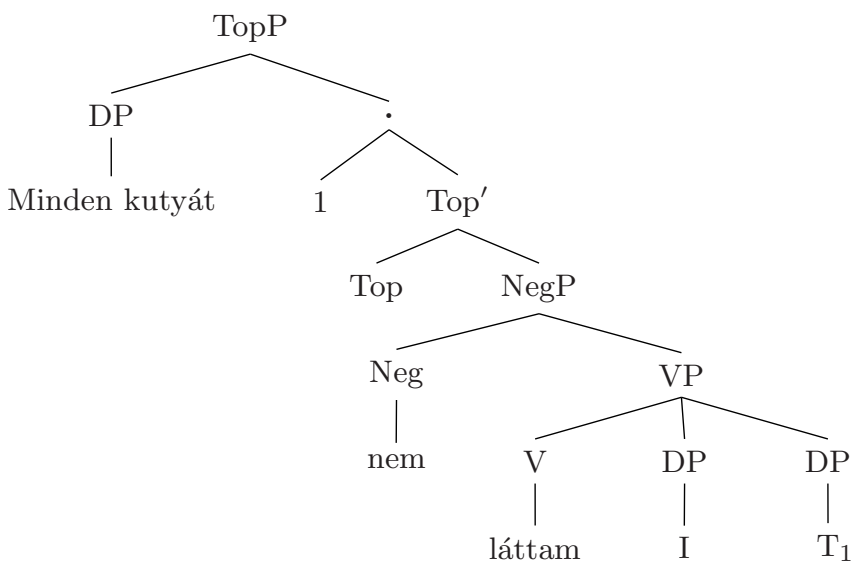

following: the property of not being seen by me does not hold of the maximal individual in the denotation of $d o g$. Since this (negative) property does not distribute down to the atoms of the above lattice, the truth of above proposition does not entail that there is no dog I have seen.

Consider now the property-denotation of the contrastive topic DP, which, following the pattern of (39), would be the property of being the sum of all atomic individuals in the denotation of $d o g$. (This property is possessed by one individual only, the maximal individual in the semilattice corresponding to the noun denotation.) The above property is abbreviated as in (53a), whereas (53b) shows the denotation of the NegP. The denotation of the TopP node of (52) is generated by means of function-argument application from the above two denotations, as indicated in $(53 \mathrm{c})$ :

(53) (a) $\llbracket$ minden kutyát $\rrbracket_{\text {property }}=\lambda \boldsymbol{x} \operatorname{ALL-DOGS}(\boldsymbol{x})$

(b) $\llbracket \mathrm{NegP} \rrbracket=\llbracket \operatorname{Top}^{\prime} \rrbracket=\neg \exists \boldsymbol{y}\left[\operatorname{saw}(\mathbf{I}, \boldsymbol{y}) \wedge \boldsymbol{Q}_{\boldsymbol{i}}(\boldsymbol{y})\right]$

(c) $\lambda \boldsymbol{Q}_{\boldsymbol{i}} \neg \exists \boldsymbol{y}\left[\operatorname{saw}(\mathbf{I}, \boldsymbol{y}) \wedge \boldsymbol{Q}_{\boldsymbol{i}}(\boldsymbol{y})\right](\lambda \boldsymbol{x} \operatorname{ALL}-\operatorname{DOGS}(\boldsymbol{x}))=$ $=\neg \exists \boldsymbol{y}[\operatorname{saw}(\mathbf{I}, \boldsymbol{y}) \wedge \operatorname{ALL}-\operatorname{DOGS}(\boldsymbol{y})]$

(53c) means that there is no individual with the property of being the sum of all dogs which I saw, which correctly reflects the truth-conditions of the sentence. In the next section we turn to sentences where the contrastive topic role is played by DPs which contain monotone decreasing or nonmonotone determiners. 


\subsection{Contrastive topic DPs with monotone decreasing and non-monotonic determiners}

In (54) below, the contrastive topic position is filled by a DP which is assumed not to be able to introduce a discourse referent (cf. Szabolcsi 1997b), and which contains a non-monotonic determiner:

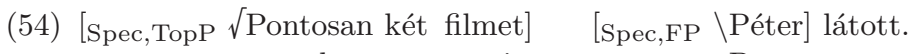

'Exactly two movies were seen by $\backslash$ PETER.'

(54) is a statement about the property of being an individual in the denotation of movie with exactly two atomic parts. The sentence expresses that Peter is the person who saw an entity with the above property. It implicates that there is at least one other property (of being an individual of the type movie with a different number of atomic parts) such that an individual with this property was seen by an alternative of Peter. It presupposes, on the one hand, that there is an invidivual who saw exactly two movies (due to the focus), and, on the other hand, that properties of being sums of movies with a particular number of atomic parts are considered relevant in the context (due to the contrastive topic).

The contrastive topic of the sentence below contains a monotone decreasing determiner:

(55) [Spec,TopP $\sqrt{\text { Háromnál kevesebb könyvet] [Spec,FP } \backslash J a ́ n o s] ~ o l v a s o t t . ~}$ three-than less book-acc John read

'Less than three books were read by \JoHn.'

(55) is about the property of being an individual in the denotation of book with less than three atomic parts. It states that John is the person who read an entity with the above property, and it implicates that there is an alternative property of sums of books such that an alternative of John read an individual with this property. The sentence presupposes that the above property has been established as relevant in the context - by being set into contrast with properties like those expressed by pontosan három könyvet 'exactly three book-acc' and háromnál több könyvet 'more than three book-acc', and that there was someone who read less than three books. However, (55) can be true even if there is no book at all which John read.

Before considering a compositional interpretation for the above sentences, note one more important observation about the contrastive topic 
constituents in them, namely, that they, at least in factual statements, must be followed by a constituent in preverbal focus position, unlike the contrastive topic DPs in (3), (19), (28), (37), (45) or (51) above. (56)(59) below illustrate some unacceptable sentences with pontosan két filmet 'exactly two movies' and háromnál kevesebb könyvet 'less than three books'. (The various reasons for the unacceptability of these sentences are discussed systematically in Gyuris 2002.)

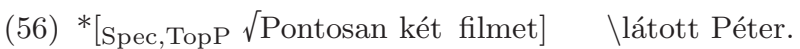
exactly two movie-acc saw Peter \#'Exactly two movies \were seen by Peter.'

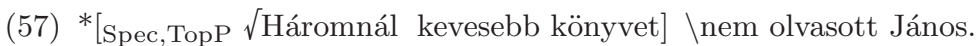
three-than less book-acc not read John \#'Less than three books \weren't read by John.'

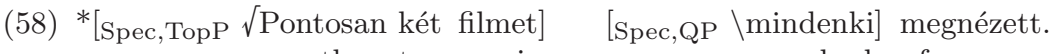
exactly two movie-acc everybody pfx-saw \#'Exactly two movies were seen by \everybody.'

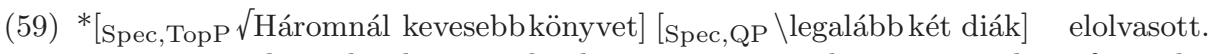
three-thanless book-acc at least twostudentpfx-read \#'Less than three books were read by at least \two students.'

We now turn to how to generate the truth-conditions of (54). (60) shows the syntactic structure associated with this sentence.

(60)

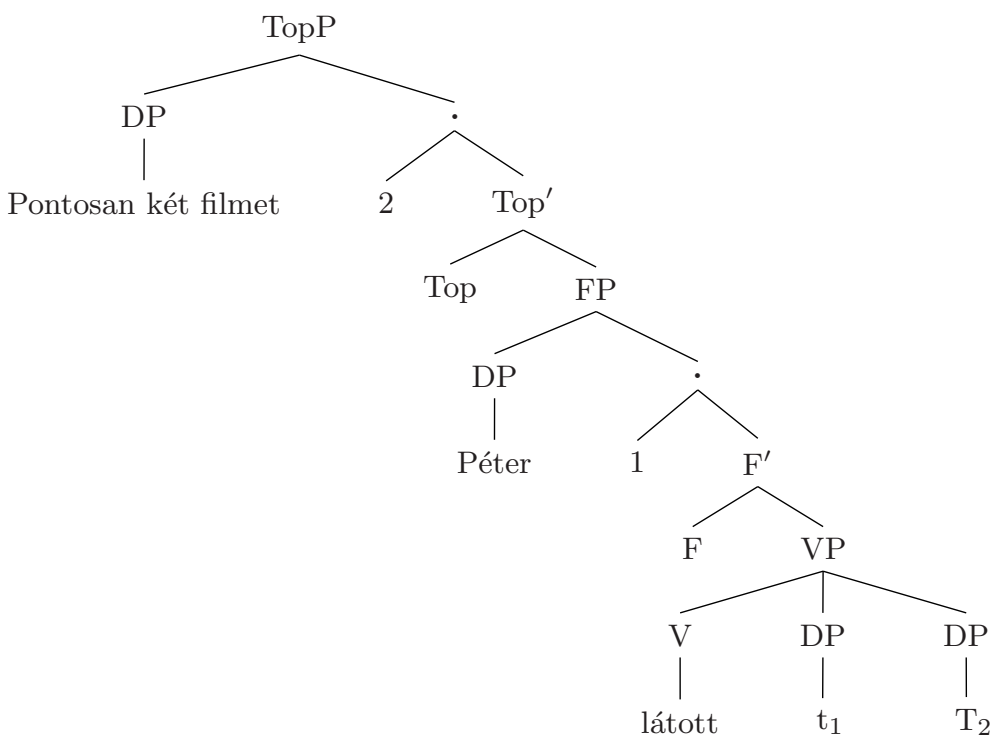


We generate the denotation of the VP in the usual manner:

(61) $\llbracket \mathrm{VP} \rrbracket=\exists y[\operatorname{saw}(x, y) \wedge Q(y)]$

The denotation of the $\mathrm{F}^{\prime}$ node is arrived at by combining the above denotation with the denotation of the focus operator, situated in F, as follows:

(62) (a) $\llbracket \mathrm{F} \rrbracket=\lambda \boldsymbol{P} \lambda \boldsymbol{z} \forall \boldsymbol{x}[\boldsymbol{P}(\boldsymbol{x}) \rightarrow \boldsymbol{x}=\boldsymbol{z}]$

(b) $\llbracket \mathrm{F}^{\prime} \rrbracket=\lambda P \lambda \boldsymbol{z} \forall \boldsymbol{x}[\boldsymbol{P}(\boldsymbol{x}) \rightarrow \boldsymbol{x}=\boldsymbol{z}](\exists \boldsymbol{y}[\operatorname{saw}(\boldsymbol{x}, \boldsymbol{y}) \wedge \boldsymbol{Q}(\mathrm{y})])=$ $=\lambda \boldsymbol{z} \forall \boldsymbol{x}[\exists \boldsymbol{y}[\operatorname{saw}(x, y) \wedge \boldsymbol{Q}(y)] \rightarrow \boldsymbol{x}=\boldsymbol{z}]$

(62b), combined with the focus denotation, yields the following as the denotation of the FP node:

(63) $\lambda \boldsymbol{z} \forall \boldsymbol{x}[\exists \boldsymbol{y}[\operatorname{saw}(\boldsymbol{x}, \boldsymbol{y}) \wedge \boldsymbol{Q}(\boldsymbol{y})] \rightarrow \boldsymbol{x}=\boldsymbol{z}](\mathbf{p})=$ $=\forall \boldsymbol{x}[\exists \boldsymbol{y}[\operatorname{saw}(\boldsymbol{x}, \boldsymbol{y}) \wedge \boldsymbol{Q}(\boldsymbol{y})] \rightarrow \boldsymbol{x}=\mathbf{p}]$

The formula in (63) means that any individual which saw an individual with the property given in the contrastive topic denotation is identical to the denotation of the focus, i.e., Peter, and thus reflects the key feature of the interpretation of the focus in Hungarian, namely, that it expresses exhaustive listing. (63) does not by itself entail that there was an individual satisfying the property specified by the focus frame, i.e., the sentence minus the focused expression. However, Hungarian sentences with a focus already presuppose that there is an entity (property, etc., depending on the assumed denotation of the focus) for which the focus frame holds, and thus the explicit postulation of the above entailment becomes unnecessary. The next formula illustrates how the interpretation of the contrastive topic is combined with that of the rest of the sentence by means of function-argument application:

(64) $\llbracket \operatorname{TopP} \rrbracket=\lambda \boldsymbol{Q} \forall \boldsymbol{x}[\exists \boldsymbol{y}[\operatorname{saw}(\boldsymbol{x}, \boldsymbol{y}) \wedge \boldsymbol{Q}(\boldsymbol{y})] \rightarrow \boldsymbol{x}=\mathbf{p}](\lambda \boldsymbol{z} \operatorname{EXACTLY-2-MOVIE}(\boldsymbol{z}))=$ $=\forall \boldsymbol{x}[\exists \boldsymbol{y}[\operatorname{saw}(\boldsymbol{x}, \boldsymbol{y}) \wedge \operatorname{EXACTLY-2-MOVIE}(\boldsymbol{y})] \rightarrow \boldsymbol{x}=\mathbf{p}]$

The above formula means that any individual which saw an entity which is a sum of exactly two movies is identical to Peter. This seems to correspond to the truth conditions of the sentence. The only remaining question is how to define the property corresponding to the contrastive topic. 
Suppose the property denoted by exactly two movies was defined according to the pattern proposed in (35), repeated here as (65), in the way illustrated in (66):

(65) the property-denotation of arbitrary DPs - first version

$\llbracket$ Det NP $\rrbracket_{\text {property }}=\lambda \boldsymbol{x}$ DET-NP $(\boldsymbol{x})={ }_{\text {def }}$

$\lambda \boldsymbol{x} . \exists \boldsymbol{S}\left(\boldsymbol{S} \in \llbracket\right.$ Det $\left.\mathrm{NP} \rrbracket_{\mathrm{GQ}} \wedge \boldsymbol{S} \subseteq \llbracket \mathrm{NP}_{\text {sing }} \rrbracket \wedge \boldsymbol{x}=\sqcup \boldsymbol{S}\right)(\boldsymbol{x})$

(66) $\lambda \boldsymbol{x}$ EXACTLY-2-MOVIE $(\boldsymbol{x})=_{\mathrm{def}}$-first version

$\lambda \boldsymbol{x} \exists \boldsymbol{S}\left(\boldsymbol{S} \in \llbracket\right.$ exactly two movies $\rrbracket_{\mathrm{GQ}} \wedge \boldsymbol{S} \subseteq \llbracket$ movie $\left.\wedge \wedge \boldsymbol{x}=\sqcup \boldsymbol{S}\right)(\boldsymbol{x})$

Note that if (66) is interpreted in a context in which the properties denoted by the DPs less than two movies, exactly two movies and more than two movies are considered relevant, then any individual with the property of having seen more than two movies, i.e., an entity which constitutes the sum of more than two movies, in fact has the property of having seen an entity which is the sum of less than two movies as well, due to the semantics of the predicate denoted by saw. This means that on the denotation of exactly two movies assumed in the context where (54) is uttered, the property formalized in (66) will be true of more than one individual, without entailing that the corresponding sentence comes out as false. To overcome the above difficulty, we propose (following a suggestion by Chris Piñon, p.c.) that the properties denoted by DPs containing monotone decreasing and non-monotonic determiners be relativized to the immediate situation, which can be achieved by postulating an implicit situation variable in the representation of the property in question. (This situation variable is not identical to the Davidsonian event variable, rather, it is to be viewed as a variable ranging over parts of possible worlds.)

(67) $\llbracket$ exactly two movies $\rrbracket_{\text {property }}=\lambda s \lambda \boldsymbol{x E X A C T L Y - 2 - M O V I E}(\boldsymbol{x})={ }_{\mathrm{def}}$ -final version

$\lambda \boldsymbol{s} \lambda \boldsymbol{x} \exists \boldsymbol{S}\left(\boldsymbol{S} \in \llbracket\right.$ exactly two movies $\rrbracket_{\mathrm{GQ}} \wedge \boldsymbol{S} \subseteq \llbracket$ movie $\rrbracket \wedge \boldsymbol{x}=$

$=\sqcup \boldsymbol{S} \wedge \neg \exists \boldsymbol{x}^{\prime}\left(\boldsymbol{x}_{\mathrm{i}} \sqsubseteq s \boldsymbol{x}^{\prime} \wedge \boldsymbol{x}^{\prime} \subseteq s \llbracket\right.$ movie $\left.\left.\rrbracket\right)\right)(\boldsymbol{x})$

Thus, according to (67), the DP exactly two movies denotes the property of being a sum of exactly two individuals which are movies and which do not constitute individual-parts of other, larger individuals in the denotation of movie in the relevant situation. Naturally, in order to be able to formally combine the property in (67) and the property denoted by the rest of the sentence it has to be assumed that the latter (as well as 
the verb denotation) also contains an abstraction over a situation variable, which, eventually, comes from the meaning of the verb. Thus, the meaning of (54) would be derived as follows:

(68) $\llbracket \mathrm{TopP} \rrbracket=\lambda \boldsymbol{Q}_{s} \lambda \boldsymbol{s} \forall \boldsymbol{x}\left[\exists \boldsymbol{y}\left[\operatorname{saw}_{\boldsymbol{s}}(\boldsymbol{x}, \boldsymbol{y}) \wedge \boldsymbol{Q}_{\boldsymbol{s}}(\boldsymbol{y})\right] \rightarrow \boldsymbol{x}=\boldsymbol{s} \mathbf{p}\right]$

$\left(\lambda s \lambda z\right.$ EXACTLY-2-MOVIE $\left._{s}(\boldsymbol{z})\right)=\lambda s \forall \boldsymbol{x}\left[\exists \boldsymbol{y}\left[\operatorname{saw}_{s}(\boldsymbol{x}, \boldsymbol{y}) \wedge\right.\right.$

$\left.\left.\operatorname{EXACTLY-2-MOVIE}_{s}(\boldsymbol{y})\right] \rightarrow \boldsymbol{x}=s \mathbf{p}\right]$

The above formula denotes the set of situations in which any individual who saw exactly two movies is identical to Peter. ${ }^{7}$

Let us turn now to (55), which contains the DP less than three books. The denotation of this sentence, following the pattern of (68), would be represented as follows:

(69) $\llbracket \mathrm{TopP} \rrbracket=\lambda \boldsymbol{Q}_{s} \lambda \boldsymbol{s} \forall \boldsymbol{x}\left[\exists \boldsymbol{y}\left[\operatorname{read}_{s}(\boldsymbol{x}, \boldsymbol{y}) \wedge \boldsymbol{Q}_{s}(\boldsymbol{y})\right] \rightarrow\right.$

$\rightarrow \boldsymbol{x}=\mathbf{j}](\lambda s \lambda \boldsymbol{z}$ LESS-THAN-3-BOOK $\boldsymbol{s}(\boldsymbol{z}))=$

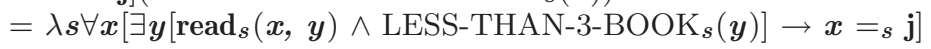

(69) means that any individual for which there is an entity which has the property of being fewer than three books but not more in the situation under discussion is identical to John. Note that on the pattern of (67), the property denoted by less than three books would be defined as in (70):

(70) $\lambda \boldsymbol{s} \lambda \boldsymbol{x}$ LESS-THAN-3-BOOK $\boldsymbol{s}(\boldsymbol{x})=_{\mathrm{def}}$-final version

$\lambda \boldsymbol{s} \lambda \boldsymbol{x} \exists \boldsymbol{S}\left(\boldsymbol{S} \in \llbracket\right.$ less than three books $\rrbracket_{\mathrm{GQ}} \wedge \boldsymbol{S} \subseteq \llbracket$ book》 $\wedge \boldsymbol{x}=$

$=\sqcup S \wedge \neg \exists x^{\prime}\left(x_{\mathrm{i}} \sqsubseteq s \boldsymbol{x}^{\prime} \wedge \boldsymbol{x}^{\prime} \subseteq s \llbracket\right.$ book $\left.\rrbracket\right)(\boldsymbol{x})$

(70) expresses that the property denoted by less than three books is the property of individuals which constitute the sum of a set in the set of

${ }^{7}$ A reviewer for Acta Linguistica remarks that the method proposed here to account for the meaning of sentences with contrastive topics can only handle examples with extensional verbs, but not the ones containing intensional verbs, verbs of creation and depiction, like the one in (i):

(i) [CT Sárkányt] [Spec,FP \Mari] rajzol (éppen).

dragon-acc Mari draws (right now)

'It is Mary who is drawing a dragon right now.'

Although we agree with the reviewer in the above respect, we wish to emphasize that the problems with the above sentence are not restricted to the use of the contrastive topic. As soon as the verbs of the types characterized above are given a denotation based on possible worlds, the properties denoted by the contrastive topics can easily be relativized to the possible worlds the verb denotation is based on, just like they are relativized to situations in (67). 
sets in the generalized quantifier denotation of the above DP which is a subset of the set of books, but where the individual itself is not part of any larger individual in the set of books in the present situation. Note that the above property would also be satisfied by the individual which constitutes the sum of the empty set, which Bonomi-Casalegno (1993) refers to as the empty group. This could account for the fact that (55) can even be true if there are no books which John read.

Generalizing the mechanism applied in (70), we can update (35), showing the general strategy for generating the property denotations for contrastive topic DPs as illustrated in (71):

(71) the property-denotation of arbitrary DPs - final version

(a) if Det is monotone increasing

$$
\begin{aligned}
& \llbracket \text { Det NP } \rrbracket_{\text {property }}=\lambda \boldsymbol{x} \mathrm{DET}_{-\mathrm{NP}}(\boldsymbol{x})={ }_{\mathrm{def}} \\
& \lambda \boldsymbol{x} \exists \boldsymbol{S}\left(\boldsymbol{S} \in \llbracket \text { Det NP} \rrbracket_{\mathrm{GQ}} \wedge \boldsymbol{S} \subseteq \llbracket \mathrm{NP}_{\text {sing }} \rrbracket \wedge \boldsymbol{x}=\sqcup \boldsymbol{S}\right)
\end{aligned}
$$

(b) if Det is monotone decreasing or non-monotonic

$$
\begin{aligned}
& \llbracket \text { Det NP } \rrbracket_{\text {property }}=\lambda \boldsymbol{x} \mathrm{DET}_{-\mathrm{NP}}(\boldsymbol{x})=_{\text {def }} \\
& \lambda \boldsymbol{x} \exists \boldsymbol{S}\left(\boldsymbol{S} \in \llbracket \text { Det NP } \rrbracket_{\mathrm{GQ}} \wedge \boldsymbol{S} \subseteq \llbracket \mathrm{NP}_{\text {sing }} \rrbracket \wedge \boldsymbol{x}=\sqcup \boldsymbol{S} \wedge \neg \exists \boldsymbol{x},\left(\boldsymbol{x}_{\mathrm{i}} \sqsubseteq_{\mathrm{s}} \boldsymbol{x}^{\prime} \wedge\right.\right. \\
& \left.\left.\wedge \boldsymbol{x}^{\prime} \subseteq_{\mathrm{s}} \llbracket \mathrm{NP}_{\text {sing }} \rrbracket\right)\right)(\boldsymbol{x})
\end{aligned}
$$

Note that although DPs with monotone increasing determiners do not require that their property denotation be relativized to a particular situation, for the sake of generality it could be assumed that the properties associated with all DPs would be derived on the pattern in (71b).

The only exception to the above general rule of deriving the propertydenotation of DPs is illustrated by the following example, where the property of plural individuals denoted by the contrastive topic expression cannot hold for any objects in the denotation of the noun:

(72) [Spec,TopP $\sqrt{\text { Semelyik film] }}[$ Spec,FP $\backslash$ Jánosnak] nem tetszett.

$$
\text { none movie John-dat not liked }
$$

'None of the movies were liked BY \JoHN.'

The denotation of the FP of (72) is shown in (73):

(73) $\llbracket[$ Spec,FP $\backslash$ Jánosnak $]$ nem tetszett $\rrbracket=$

$$
=\lambda \boldsymbol{Q}_{s} \lambda s \forall \boldsymbol{x}\left[\neg \exists \boldsymbol{y}\left[\operatorname{liked}_{s}{ }^{\prime}(\boldsymbol{x}, \boldsymbol{y}) \wedge \boldsymbol{Q}_{s}(\boldsymbol{y})\right] \rightarrow \boldsymbol{x}={ }_{s} \boldsymbol{j}\right]
$$

The above formula means that among all individuals it is John for whom there is no entity with the $\boldsymbol{Q}_{s}$ property in the relevant situation which he liked. Intuitively, (72) means that it is John for whom there is no entity 
with the property of being a movie which he liked. This means that the property denoted by the contrastive topic of (72) cannot be identical to the property of not being a movie, which would appear to be the interpretation of this DP in isolation. The apparent mismatch between the interpretation of the contrastive topic taken in isolation versus taken as part of the meaning of the sentence is due to the fact that Hungarian is a negative concord language. The DP semelyik film 'none of the movies' never appears without sentential negation (disregarding elliptical utterances), and thus it will do no harm if it is interpreted as denoting the property of being a movie. If the negative quantifier of (72) is replaced by a so-called non-D(iscourse)-linked variant of it, which lacks reference to the context, the sentence is out, as illustrated in (74).

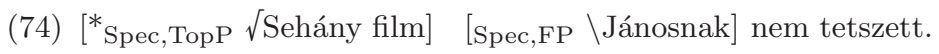
\#'No movie was liked BY \JoHN.'

John-dat not liked

The above data provide an additional argument for the view that explicit reference to the situation has to be built into the denotation of the contrastive topic in (72). (75) shows the proposed denotation of the DP semelyik film 'none of the movies', whereas (76) illustrates how the above property is combined with the denotation of the rest of the sentence:

(75) $\llbracket$ semelyik film $\rrbracket=\lambda s \lambda z \operatorname{movie}_{s}{ }^{\prime}(z)$

(76) $\lambda \boldsymbol{Q}_{s} \lambda s \forall \boldsymbol{x}\left[\neg \exists \boldsymbol{y}\left[\operatorname{liked}_{s}{ }^{\prime}(\boldsymbol{x}, \boldsymbol{y}) \wedge \boldsymbol{Q}_{s}(\boldsymbol{y})\right] \rightarrow \boldsymbol{x}={ }_{s} \mathbf{j}\right]\left(\lambda s \lambda \boldsymbol{z}\right.$ movie $\left._{s}{ }^{\prime}(\boldsymbol{z})\right)=$ $=\lambda s \forall \boldsymbol{x}\left[\neg \exists \boldsymbol{y}\left[\right.\right.$ liked $\left.\left._{s}{ }^{\prime}(\boldsymbol{x}, \boldsymbol{y}) \wedge \operatorname{movie}_{s}{ }^{\prime}(\boldsymbol{y})\right] \rightarrow \boldsymbol{x}=s \mathbf{j}\right]=$

$\left.=\lambda s \forall \boldsymbol{x}\left[\neg \exists \boldsymbol{y}\left[\operatorname{liked}_{s}{ }^{\prime}(\boldsymbol{x}, \boldsymbol{y}) \wedge \operatorname{movie}_{s}{ }^{\prime}(\boldsymbol{y})\right]\right] \rightarrow \boldsymbol{x}={ }_{s \mathbf{j}}\right]$

(76) expresses that any individual for which there is no entity which he liked and which has the property of being identical to any of the movies in the context is identical to John, which corresponds to the intuitive interpretation of the sentence.

\section{Summary}

We have proposed an alternative to Manfred Krifka's theory of scope inversion under the rise fall intonation which is not specific to German. We have argued that a left-peripheral quantifier pronounced with a (fall-)rise is in a topic position (Spec,TopP). A topic phrase must refer to an individual already present in the domain of discourse - that which will be 
predicated about in the sentence; however, non-individual-denoting expressions, among them quantifiers, can also be made suitable for the topic role if they are interpreted as properties which the rest of the sentence predicates a (higher-order) property about. A quantifier functioning as a contrastive topic denotes a property of plural individuals, and its apparent narrow scope arises from the fact that it is considered to be a predicate over a variable inherent in the lexical representation of the verb.

\section{References}

Alberti, Gábor - Anna Medve 2000. Focus constructions and the "scope-inversion puzzle" in Hungarian. In: Gábor Alberti-István Kenesei (eds): Papers from the Pécs Conference. Approaches to Hungarian 7, 93-118. JATEPress, Szeged.

Barwise, Jon-Robin Cooper 1981. Generalized quantifiers and natural language. In: Linguistics and Philosophy 4:159-219.

Beghelli, Filippo - Tim Stowell 1997. Distributivity and negation: the syntax of each and every. In: Szabolcsi (1997c, 71-108).

Bonomi, Andrea-Paolo Casalegno 1993. Only: association with focus in event semantics. In: Natural Language Semantics $2: 1-45$.

Brody, Michael 1990. Some remarks on the focus field in Hungarian. In: UCL Working Papers in Linguistics $2: 201-25$.

Büring, Daniel 1997. The great scope inversion conspiracy. In: Linguistics and Philosophy $20: 175-94$.

Carlson, Gregory 1977. A unified analysis of the English bare plural. In: Linguistics and Philosophy $1: 413-57$.

Chomsky, Noam 1995. The Minimalist Program. MIT Press, Cambridge MA.

Cohen, Ariel 1999. Review article on Veerle van Geenhoven: Semantic incorporation and indefinite descriptions: semantic and syntactic aspects of noun incorporation in West Greenlandic. In: Linguistics $37: 739-51$.

Cresti, Diana 1993. Extraction and reconstruction. In: Natural Language Semantics $3: 79-122$.

É. Kiss, Katalin 1991. Logical structure in syntactic structure: the case of Hungarian. In: James Huang-Robert May (eds): Logical structure and syntactic structure, 111-48. Reidel, Dordrecht.

É. Kiss, Katalin 1994. Sentence structure and word order. In: Ferenc Kiefer-Katalin É. Kiss (eds): The syntactic structure of Hungarian, 1-90. Academic Press, San Diego.

É. Kiss, Katalin 1995. Introduction. In: Katalin É. Kiss (ed.): Discourse configurational languages, 1-40. Oxford University Press, Oxford.

É. Kiss, Katalin 1998. Identificational focus versus information focus. In: Language $74: 245-73$.

Acta Linguistica Hungarica 50, 2003 
Frey, Werner 1993. Syntaktische Bedingungen für die semantische Repräsentation: Über Bindung, implizite Argumente und Skopus (Studia Grammatica XXXV). Akademie-Verlag, Berlin.

Geenhoven, Veerle van 1996. Semantic incorporation and indefinite descriptions. Doctoral dissertation, University of Tübingen.

Gyuris, Beáta 2002. The semantics of contrastive topics in Hungarian. Doctoral dissertation, Eötvös Loránd University, Budapest. (HTTP: //BUDLING.NYTUD.HU/ GYURIS/THESIS.HTML)

Heim, Irene-Angelika Kratzer 1998. Semantics in Generative Grammar. Blackwell, Cambridge MA \& Oxford.

Höhle, Tilman 1991. On reconstruction and coordination. In: Hubert Haider-Klaus Netter (eds): Representation and derivation in the theory of grammar, 138-97. Reidel, Dordrecht.

Hunyadi, László 1984. A kétszeres tagadásról a magyarban [On double negation in Hungarian]. In: Általános Nyelvészeti Tanulmányok 15 : 65-73.

Jackendoff, Ray 1972. Semantic interpretation in generative grammar. MIT Press, Cambridge MA.

Jacobs, Joachim 1997. I-Topikalisierung. In: Linguistische Berichte 168:91-133.

Komlósy, András 1992. Régensek és vonzatok [Valence and government]. In: Ferenc Kiefer (ed.): Strukturális magyar nyelvtan 1. Mondattan [A structural grammar of Hungarian 1. Syntax], 299-527. Akadémiai Kiadó, Budapest.

Krifka, Manfred 1998. Scope inversion under the rise fall contour in German. In: Linguistic Inquiry $29: 75-112$.

Kuno, Susumu 1973. Japanese grammar. MIT Press, Cambridge MA.

Kuroda, Sige-Yuki 1972. The categorical and the thetic judgment. In: Foundations of Language $9: 153-85$.

Liberman, Mark - Ivan Sag 1974. Prosodic form and discourse function. In: Papers from the Tenth Regional Meeting of the Chicago Linguistic Society. Chicago Linguistic Society, University of Chicago.

Link, Godehard 1983. The logical analysis of plurals and mass terms, a lattice-theoretic approach. In: Rainer Bäuerle-Christoph Schwarze-Arnim von Stechow (eds): Meaning, use, and interpretation of language, 302-23. De Gruyter, Berlin.

Maleczki, Márta 1995. A magyar főnevek és determinánsok interpretációja strukturált tartományú modellekben [Interpreting Hungarian nouns and determiners in semantic models with structured domains]. In: Néprajz és Nyelvtudomány 36 : 199-234.

Molnár, Valéria 1998. Topic in focus: the syntax, phonology, semantics, and pragmatics of the so-called "contrastive topic" in Hungarian and German. In: Acta Linguistica Hungarica $45: 89-166$.

Piñón, Christopher 2001. Definiteness effect verbs and aspect in Hungarian. Paper presented at the 5th International Conference on the Structure of Hungarian, May 24-26, 2001, Budapest.

Reinhart, Tanya 1983. Anaphora and semantic interpretation. Croom Helm, London. 
Rooth, Mats 1985. Association with Focus. Doctoral dissertation, University of Massachusetts, Amherst.

Sasse, Hans-Jürgen 1987. The thetic/categorical distinction revisited. In: Linguistics $25: 511-80$.

Szabolcsi, Anna 1997a. Background notions in lattice theory and generalized quantifiers. In: Szabolcsi (1997c, 1-27).

Szabolcsi, Anna 1997b. Strategies for scope taking. In: Szabolcsi (1997c, 109-54).

Szabolcsi, Anna (ed.) 1997c. Ways of scope taking. Kluwer, Dordrecht.

Address of the authors: Katalin É. Kiss-Beáta Gyuris Research Institute for Linguistics

Hungarian Academy of Sciences

Benczúr utca 33.

H-1068 Budapest

\{ekiss|gyuris\}@nytud.hu 